\title{
Role of Computed Tomography in Intestinal Obstruction
}

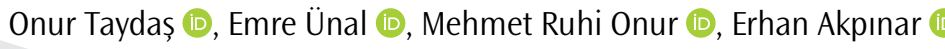

Intestinal obstructions constitute a significant proportion of all emergency department admissions for abdominal pain and may lead to significant mortality and morbidity rates when left untreated. Small and large bowel obstructions may possess different etiologies and different clinical manifestations; yet, computed tomography (CT) is the imaging method of choice for both. Images need to be meticulously interpreted; in that, CT findings may be critical in deciding about a surgical intervention. CT examinations should be conducted using an intravenous contrast material, and axial images and reformatted sagittal and coronal plane images should be evaluated simultaneously. Presence of the obstruction, location of the transition point, etiology, and possible secondary complications should be looked for.

Keywords: Intestinal obstruction, computed tomography, radiology

ORCID IDs of all authors: 0.T. 0000-0002-98817240; E.Ü. 0000-0002-1520-2487; M.R.0. 0000-00031732-7862; E.A. 0000-0001-8245-4804.

Department of Radiology, Hacettepe University School of Medicine, Ankara, Turkey

\section{Address for Correspondence:}

Onur Taydaș

E-mail: taydasonur@gmail.com

Received: 27.03.2017

Accepted: 07.08.2017

(C) Copyright 2018 by Available online at istanbulmedicaljournal.org

\section{Introduction}

Mechanical bowel obstruction constitutes $15 \%$ of the patients who consult to emergency services due to abdominal pain (1). In addition, approximately $20 \%$ of acute abdominal surgeries are performed due to bowel obstruction (2). The responsibility of a radiologist in a suspicion of intestinal obstruction is to detect the presence of obstruction and determine its location, transition point, and cause and to question the presence of complications and the presence of the findings with a clinical significance:

- Total or complete obstruction: It means that fluid and gas passages ahead of the obstruction level are not observed.

- Incomplete or partial obstruction: It refers to a quantity of fluid and gas passages ahead of the obstruction level.

- Closed-loop obstruction: It refers to the obstruction of both distal and proximal ends of an intestinal segment. The risk of complications is high $(3,4)$.

Intestinal obstruction leads to abdominal distention as a result of gas and fluid accumulation in the intestine. The increase in distention and intraluminal pressure leads to an increase in peristaltism in the first stage, whereas it leads to the opposite effect in the later period. Bacterial overgrowth occurs depending on the deterioration in peristaltism, and the passage of these bacteria and the toxins produced into the blood and lymphatic circulation increases. Hence, there is a risk of sepsis in untreated obstructions. If distension progresses, firstly, venous circulation and then arterial circulation is disrupted due to pressure increase. This leads to perforation and necrosis. This risk is greater in closed-loop obstructions $(2,3)$.

Clinically, the most important findings are abdominal pain, vomiting, swelling in the stomach, a decrease in gas and stool. While the abdominal pain is initially in a colic style, it becomes permanent due to the decrease of peristaltism in the following period.

Although the first preferred imaging method in intestinal obstructions is classically standing direct abdominal radiograph, it has a fairly limited role in the diagnosis because of the differences among interpreters and the limited information it provides about the cause of obstruction $(5,6)$. However, computed tomography (CT) can be used safely in determining the presence of obstruction, the location of the transition point, and the presence of closed-loop obstruction and complications. The sensitivity of CT in the diagnosis of obstruction is $82-100 \%$, which is quite high (7). Although the majority of patients can be treated without the need for surgery, because the mortality risk increases to $25 \%$ in the case of delayed diagnosis, early diagnosis and treatment of small bowel obstruction is of great importance (8). In addition, a CT examination 
obtained by intravenous (IV) contrast agent may also show the presence of a mesenteric vascular event (MVE), which is clinically confused with intestinal obstruction or accompanies the obstruction. Distinguishing MVE from intestinal obstruction is often not possible clinically.

Colon obstructions occur 4-5 times less frequently than small bowel obstructions, and they are mostly seen in advancedage patients. Unlike small bowel obstruction, it is more insidious and therefore diagnosed late (9). In patients with a competent ileocecal valve, colon obstruction develops as a closed-loop obstruction (10). According to the Laplace's rule, the cecum is the first to be affected by the increased pressure, and therefore the risk of ischemia and perforation is the greatest in the cecum (11). In the diagnosis of colon obstruction, the sensitivity of CT is $96 \%$, and the specificity is 93\%, and the CT is the first choice for imaging (12).

\section{CT Technique}

Although there are differences among the centers, an abdominal CT examination is obtained in the $60^{\text {th }}-70^{\text {th }}$ seconds after IV contrast material injection (portal venous phase), which includes the area between the superior level of the diaphragm and the inferior adjacent area of the symphysis pubis $(4,13)$. The use of IV contrast agent is routinely recommended for the evaluation of ischemia. Coronal and sagittal multiplanar reformat images are useful in assessing the transition point and the presence of a closed-loop obstruction (14). The use of oral contrast agent (barium or iodized) remains controversial. The advantage of using an oral contrast agent is that complete obstruction can be excluded with the passage of the oral contrast agent to the distal part of the obstruction. However, it renders the evaluation of ischemia difficult by reducing the contrast between the lumen and the intestinal wall, and it may cause delay in the treatment because it necessitates a 2-3hour waiting period after the oral administration of the contrast agent (15). CT enterography is not a suitable examination for small bowel obstruction, as it requires at least 1 liter of low attenuation fluid intake (16). Alternatively, a contrast agent can be given through the rectum in colon obstructions (10).

\section{Evaluation of CT Findings}

\section{The presence of obstruction}

The measurement of the small bowel segment being higher than $2.5 \mathrm{~cm}$ from the outer wall to the outer wall is the most important criterion for the diagnosis of small bowel obstruction (17). The intestinal segments at the distal region appear to be decompressed. Air-liquid levels and rosary grain appearance can be monitored in direct radiography (4). In case of chronic or severe obstruction, depending on the mixture of small intestine contents, gas, and stasis, a feces-like appearance, as in the colon, occurs in the obstructed small intestine segment immediately in the proximal part of the transition point in the lumen. This finding is called "small bowel feces sign," and it is seen in $5-7 \%$ of small bowel obstructions (18) (Figure 1). The small bowel feces sign is a good marker for the detection of the transition point in the presence of obstruction.

The first attention-grabbing sign in colon obstructions is dilatation of the colon. The normal colon caliber is $3-8 \mathrm{~cm}$. Dilation suggest obstruction. The presence of air-fluid levels in the loops of the colon indicates the presence of acute obstruction (10). A reliable way of distinguishing colon obstruction from chronic processes (constipation, etc.) leading to dilatation in the bowel is to be able to reveal whether dilatation affects the cecum. The diameter of the cecum increases diffusely and disproportionately in obstruction, but such a sign is not observed in other causes of dilatation (19).

\section{Determination of the transition point}

The transition point refers to the caliber change between the dilated proximal small intestine segment and the collapsed distal small intestine segment. Detecting the transition point is important, particularly in terms of finding the cause of obstruction (4). It has been reported that in intestinal obstructions, the transition point can be detected using CT at a rate of $63-93 \%$ (20). While axial sections are assessed to determine the transition point, evaluation should be made from the rectum to the proximal part as well as from the stomach to the distal part. In addition, coronal and sagittal multiplanar sections should be examined, and the presence of small intestine feces sign should absolutely be examined. In cases where the transition point in the intestinal obstruction cannot be detected directly in $\mathrm{CT}$, it is necessary to comprehensively examine the region where the mesenteric contamination is most intense. It is known that the location of the most intense mesenteric contamination is close to the transition point (21).

\section{Determining the cause of obstruction}

The most common cause of intestinal obstruction in western societies is adhesions, and hernias and cancers can be mentioned among the other most common causes, respectively. These three causes are found in about $80 \%$ of all patients. Other causes are Crohn's disease, volvulus, gallstones, foreign bodies, bezoars, trauma, and iatrogenic (22). The determination of the cause leading to small bowel obstruction usually depends on locating the transition point. While intrinsic causes usually lead to thickening of the intestinal wall, extrinsic causes are recognized by the findings of external compression and the effect of a mass (23).

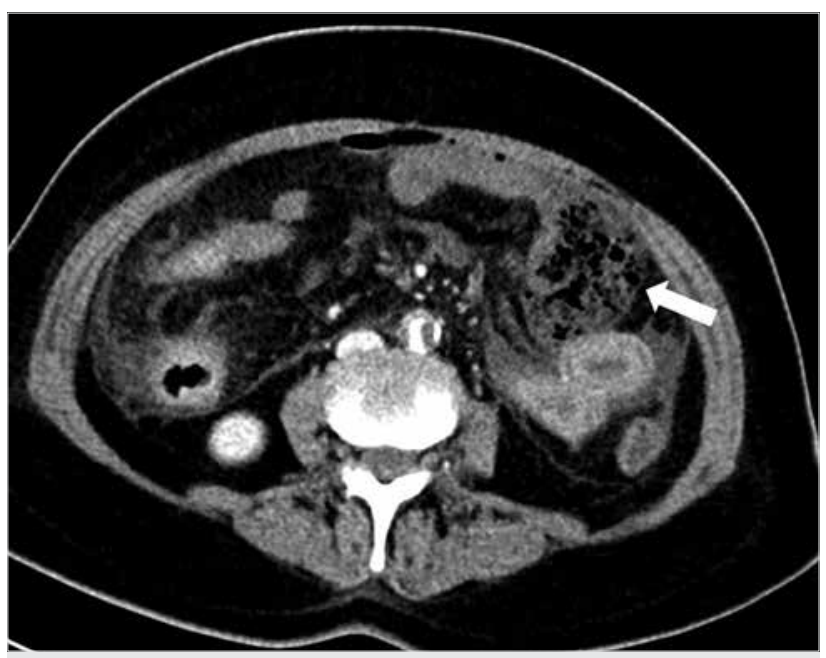

Figure 1. "Small bowel feces sign" (arrow) at the level of transition point in the lumen of the small bowel is observed in an axial contrastenhanced CT image of the 55-year-old male patient with small bowel obstruction. 

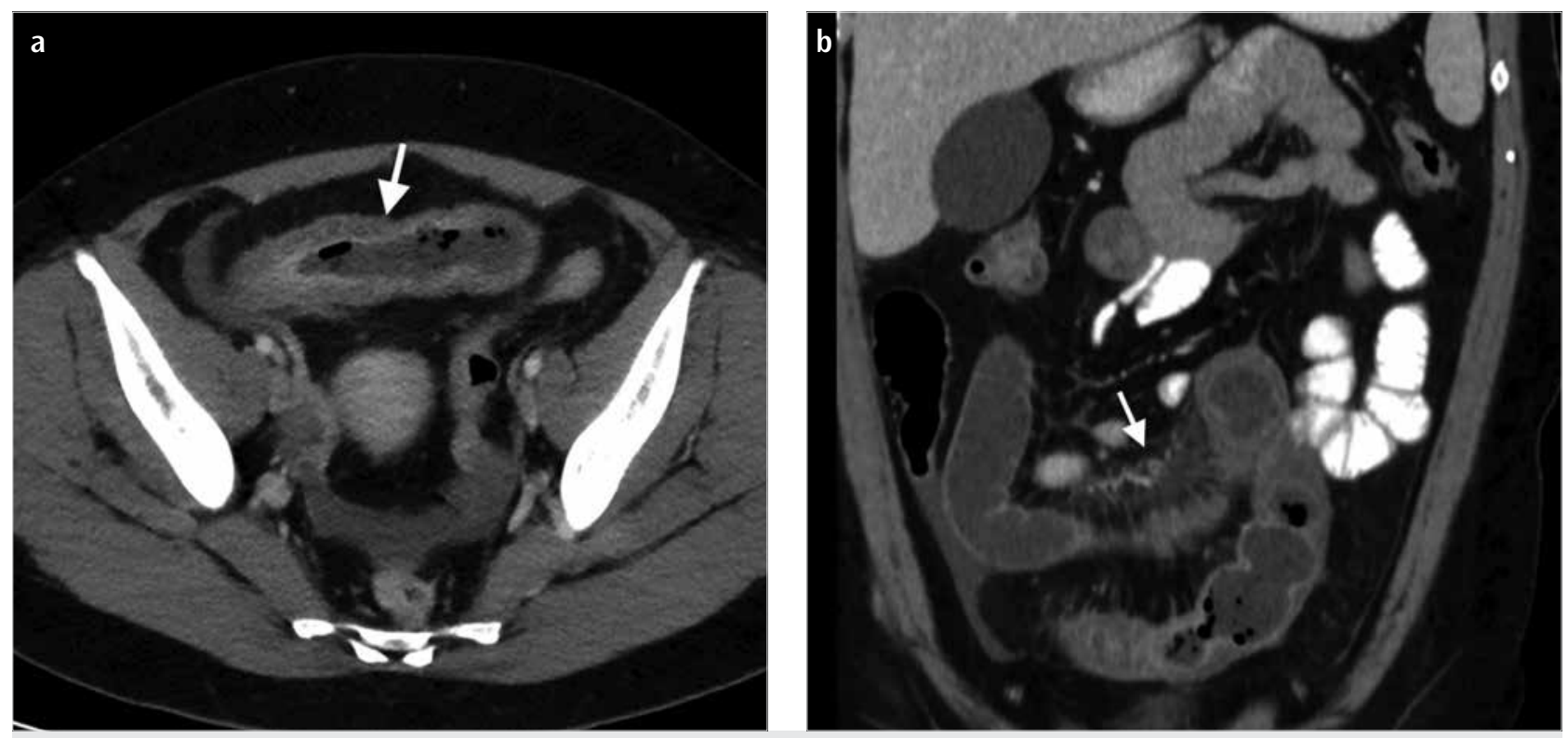

Figure 2. a, b. Terminal ileum thickening and increased contrast enhancement (arrow) are observed in the axial contrast-enhanced CT image of a 40-year-old female patient who had Crohn's disease and in whom small bowel obstruction developed. (a) The patient's coronal reconstruction image shows contamination of the surrounding fat tissue and a "comb sign" (arrowhead) formed by the mesenteric vessels (b)

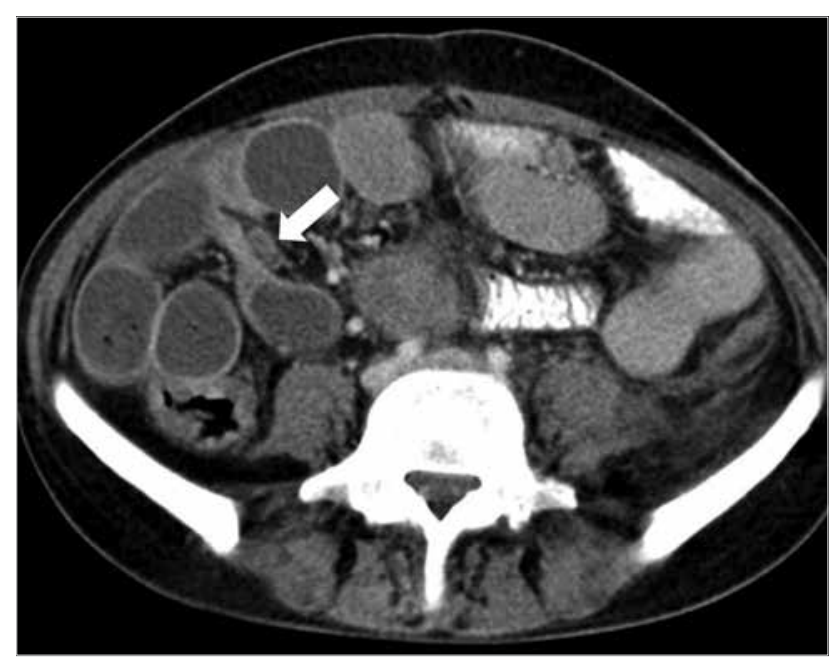

Figure 3. Small intestine obstruction and an implant at the level of transition point (arrow) are seen in the axial contrast-enhanced CT of a 44-year-old woman with peritoneal carcinomatosis.

\section{Intrinsic causes}

\section{Crohn's disease}

It may cause bowel obstruction because of transmural wall thickening due to acute inflammation. In addition, obstruction may also develop due to sequel narrowing in the affected segment in the chronic process (24). Distinguishing these two situations is very important in terms of patient follow-up. In acute inflammation, a contrast enhancement in the bowel wall in CT, contamination in the surrounding fat tissue, and a "comb sign" due to enlargement of the surrounding mesenteric vessels are observed (Figure 2). The presence of these findings suggests that the patient will probably benefit from the medical treatment. Otherwise, a surgical treatment should be considered (25).

\section{Neoplasms}

Primary small bowel neoplasms are rare. If they lead to obstruction, they are seen as asymmetric and irregular mural thick- ening at the transition point in CT. Metastases are more commonly seen than primary neoplasms and can be distinguished by their extraserosal involvements at the transition point level in CT (Figure 3) (26). The most common cause in colon obstruction is colon cancer. There is a $30 \%$ mortality risk in colonic obstruction developing due to tumors (27). They appear in CT as short segment wall thickening, which narrows the colon segment or as a contrasting soft tissue mass. In particular, lymphadenopathies around the colon should lead to a suspicion for malignancy (28).

\section{Intussusception}

It is a rare cause in adults and accounts for less than $5 \%$ of all small bowel obstructions. Almost all cases have a "lead point" that causes invagination. The appearance of intestine inside the intestine is typical, which is described as a "target sign" in CT (29).

\section{Radiation enteritis}

The most radiosensitive part of the gastrointestinal tract is the small intestines. In the acute phase (first few weeks), it may cause mucosal contrast enhancement in $\mathrm{CT}$ and obstruction due to bowel wall thickening. The chronic period may occur years later. Obstruction may develop due to strictures in this period (30).

\section{Diverticulitis}

It may cause inflammation and intestinal wall edema in the acute period and cause obstruction due to strictures in the chronic period. Sigmoid is most commonly seen in the colon (31). It is characterized by segmental, symmetric wall thickening and hyperemia, which involves segments longer than $10 \mathrm{~cm}$ in CT. Pericolonic inflammation and contamination in mesenteric fat tissues should suggest diverticulitis particularly (32). In contrast, the presence of short-segment involvement and lymphadenopathies around suggests malignancy. However, in some cases, it may not be possible to exclude malignancy. Therefore, a post-episode colonoscopic evaluation is recommended in patients undergoing diverticulitis episode (33). 


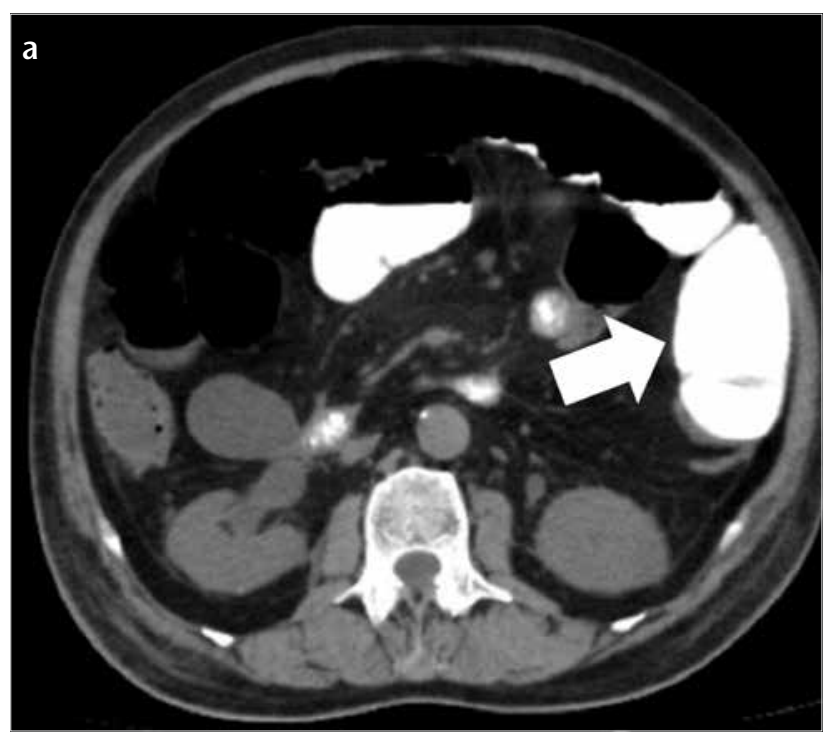

\section{Extrinsic causes}

\section{Adhesions}

It is the most common cause of small bowel obstructions and is seen in $85 \%$ of patients. This percentage increases to $93 \%$ in patients with a surgical history (22). However, it should not be forgotten that $10-15 \%$ of the adhesions may develop due to a probable previous inflammation in patients who have no surgical history (34). Diagnosis is mainly based on the exclusion of other causes. A history of surgery and stretching in adjacent bowels are helpful in the diagnosis (Figure 4) (35).

\section{Hernia}

It is the second most common cause of small bowel obstruction. Although obstructions related to external hernias (Figure 5) are seen, internal hernias may also cause obstruction (Figure 6). In
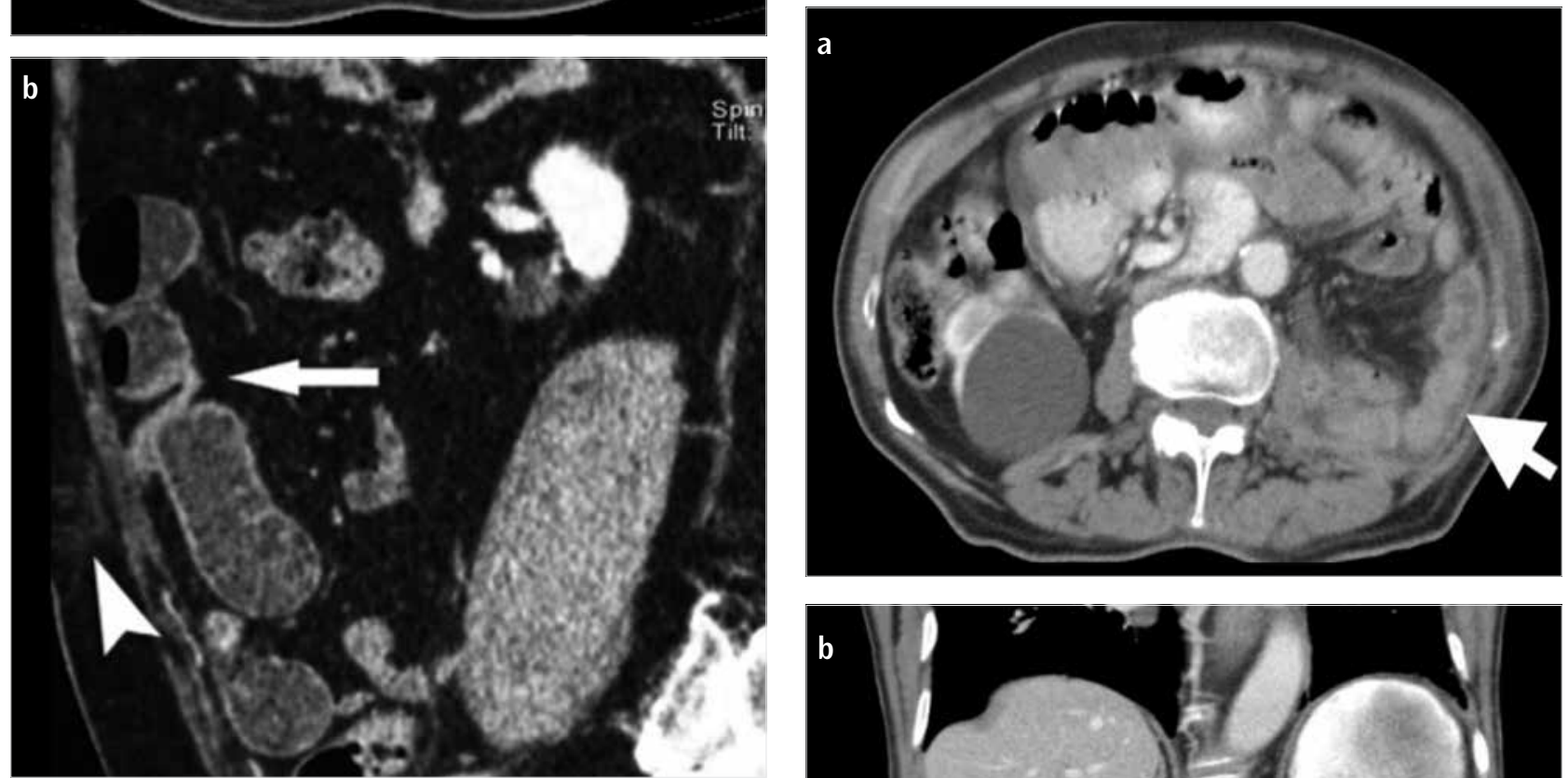

Figure 4. a, $\mathbf{b}$. In the axial contrast-enhanced $C$ image obtained 6 months after the abdominal surgery in a 50-year-old male patient, small bowel obstruction developing due to the adhesions in the surgical site results in dilatation of the proximal loops (arrow). (a) Adhesion (arrow) and the under-skin appearance of surgery (arrowhead) are observed in the coronal CT image. (b)

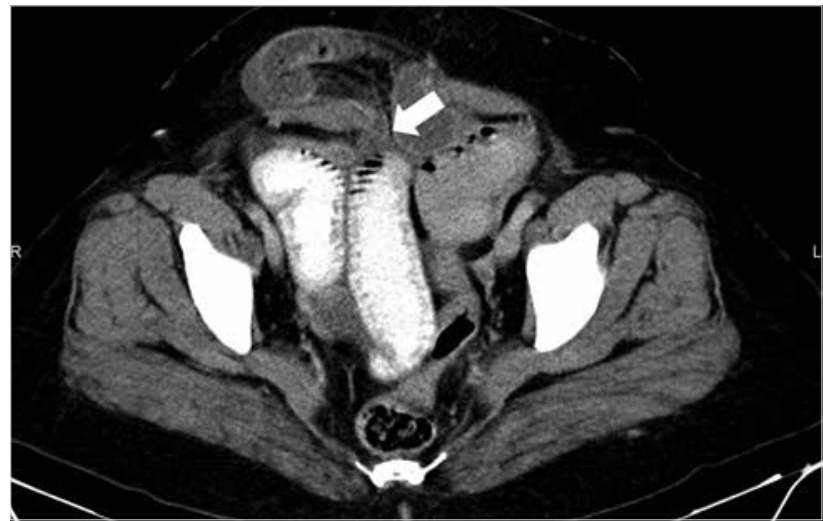

Figure 5. Decrease in bowel caliber due to compression in the distal part of hernia sac (arrow) is observed in the axial contrast-enhanced CT of a 51-yearold female patient with intestinal obstruction due to umbilical hernia.

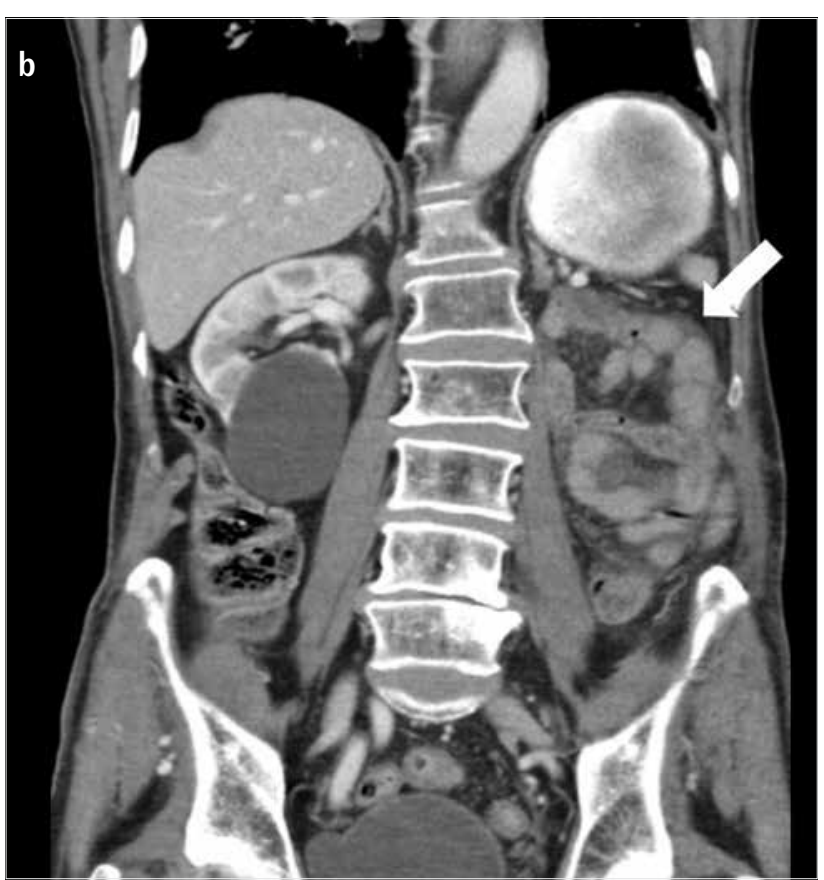

Figure 6. a, b. Dilatation in the proximal jejunal loops due to left paraduodenal internal hernia is observed in the axial (A) and coronal (B) CT of a 43-year-old male patient 1 year after left nephrectomy. In this case, the finding that led to the diagnosis of internal hernia is that the jejunal loops had a left retroperitoneal location because of internal herniation after nephrectomy. 
addition, it should not be forgotten that the presence of internal hernia can only be detected radiologically (36).

\section{Volvulus}

It is the cause of about $10-15 \%$ of colonic obstruction cases. It is often seen in advanced-age patients. It indicates the rotation of the intestine around itself or around another intestinal segment. Surgical intervention is usually required when the rotation is more than 360 degrees. The ischemic risk is higher due to vascular compression. It is most commonly seen in the sigmoid colon (37). Many signs, such as "coffee bean, bird beak, reverse U sign," which can be observed in the direct radiography, have been defined in the diagnosis. The "vortex sign," which can be seen in CT and indicates the vessels wrapped by the intestines, is typical for volvulus. The displacement of the cecum is a finding that helps to establish a diagnosis in cecal volvulus (38).

\section{Intraluminal causes}

\section{Bile stone ileus}

It is a rare complication of recurrent cholecystitis that occurs because of the passage of the bile stone to the gallbladder or other bile tracts through the bilioenteric fistula (Figure 7). Classically, the rigler triad, including pneumobilia, ectopic gallstones, and small bowel obstruction, is found in patients (39).

\section{Distal intestinal obstruction syndrome}

It develops depending on cystic fibrosis in young adults. It is caused by intestinal contents that become solid due to insufficient
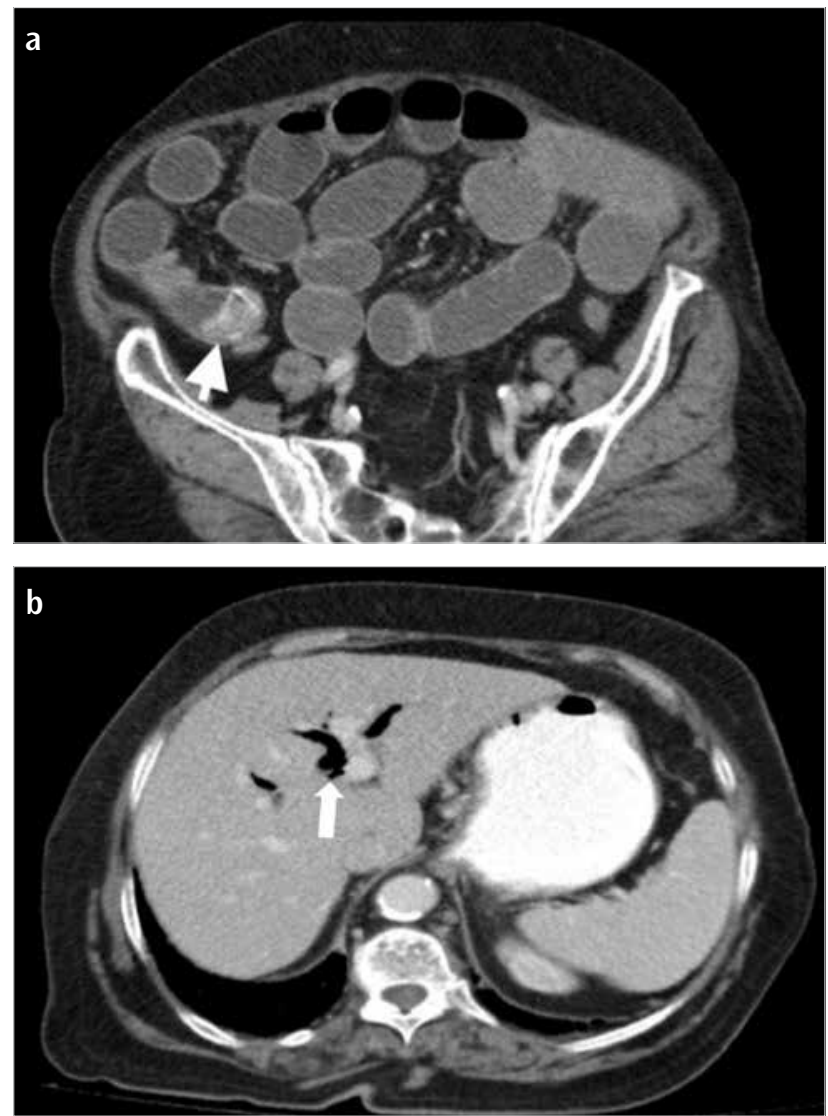

Figure 7. a, b. Bowel obstruction (arrow) is seen in the axial CT of a 50-year-old female patient who consulted with the complaint of abdominal pain. (a) In the section at the level of liver, air (arrow) is seen in the intrahepatic bile ducts secondary to the bilioenteric fistula. (b) intestinal secretion. In CT, filling defects are seen in places where secretion accumulates in the small intestines. An accurate diagnosis is very important because the treatment is medical (40).

\section{Other intraluminal causes}

Bezoars are commonly seen in patients surgically treated for gastric outflow (41). Sclerosing encapsulitis developing due to peritoneal dialysis can also lead to bowel obstruction, and a "cocoon appearance" in CT is typical for the diagnosis (Figure 8) (42). In addition, although rare in adults, swallowed foreign bodies possibly leading to obstruction should also be considered (Figure 9) (43).

\section{The presence of a complicated obstruction}

A complicated obstruction includes bowel obstruction concepts that have caused closed-loop obstruction and intestinal ischemia.

\section{Closed-loop obstruction}

It is defined as the isolation of the affected intestinal segment occluded both in the distal and proximal segments from the gastrointestinal tract (Figure 10). This isolated segment rapidly dilates
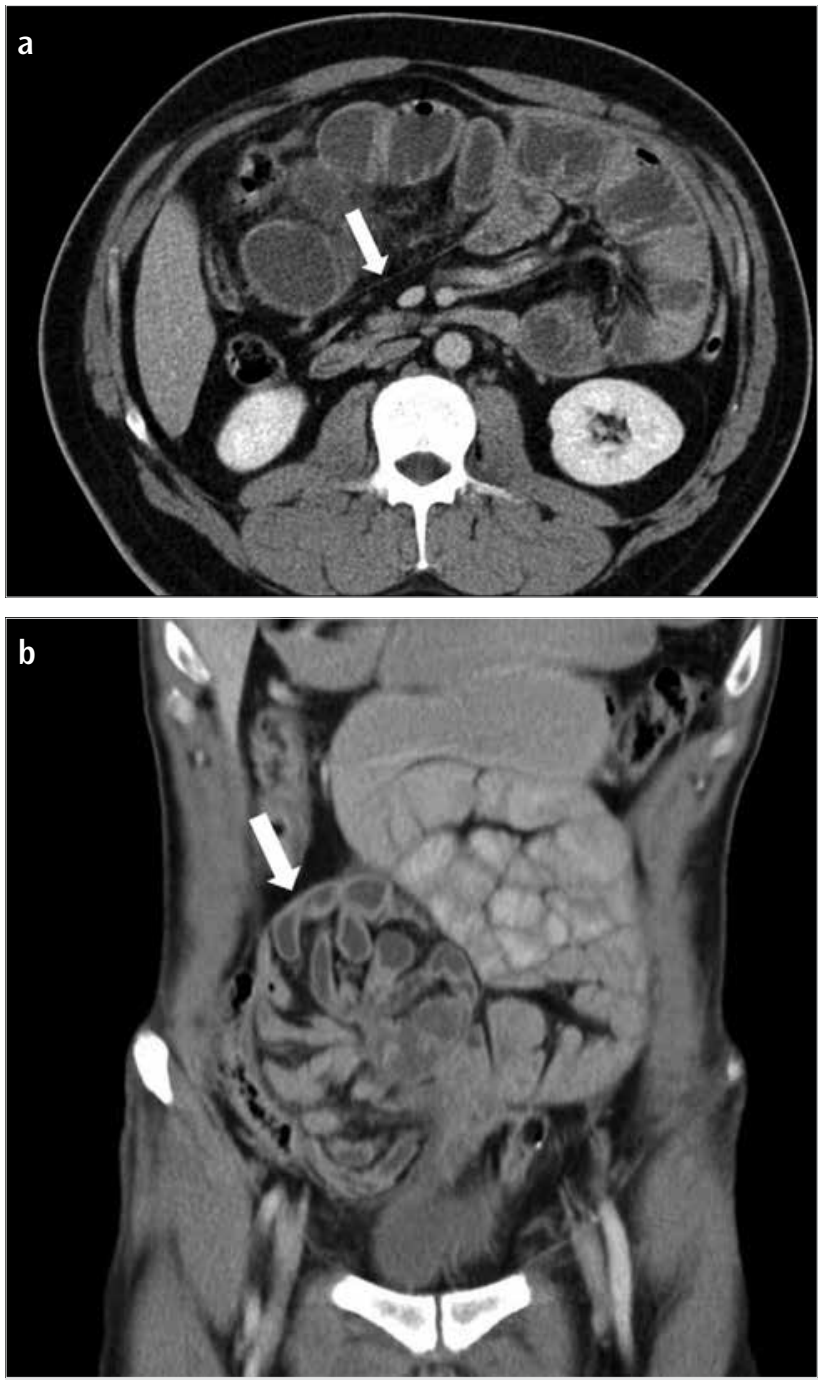

Figure 8. a, b. Sclerosing encapsulitis and intestinal obstruction developing secondary to chronic fibrotic changes (arrow) around the intestinal loops are observed in the axial (A) and coronal CT of a 53-yearold male patient undergoing peritoneal dialysis. Coronal $\mathrm{CT}$ shows a typical "cocoon appearance" (arrow) of the sclerosing encapsulitis. (b) 
as it will continue to secrete, and the dilatation results in ischemia. In addition, volvulus may also develop due to peristaltism in the proximal and distal bowel segments (44). Although the most common cause is adhesions, it may also occur due to internal hernias. It has also been reported that the risk increases in patients undergoing the Roux-en-Y surgery (45). In CT, " $U$," "C," and "coffee bean" appearance is helpful in the diagnosis. Sagittal and coronal reformatted images should also be evaluated because routine diagnostic findings can easily be missed out in routine axial images (46). In complicated and volvulus cases, the vortex sign may also be seen (47). Because the colon obstructions are disposed to become closed-loop obstruction, the risk of complications is high. Because closed-loop obstructions frequently result in ischemia, the presence of ischemia should be carefully researched (3).

\section{Bowel ischemia}

It occurs in about $10 \%$ of patients with small bowel obstruction. It has high mortality. The sensitivity of $\mathrm{CT}$ for detecting ischemia is $83 \%$, and the specificity is $92 \%$ (48). Wall thickening in the affected intestinal segments, abnormal reduction of wall contrast enhancement, pneumothosis, mesenteric
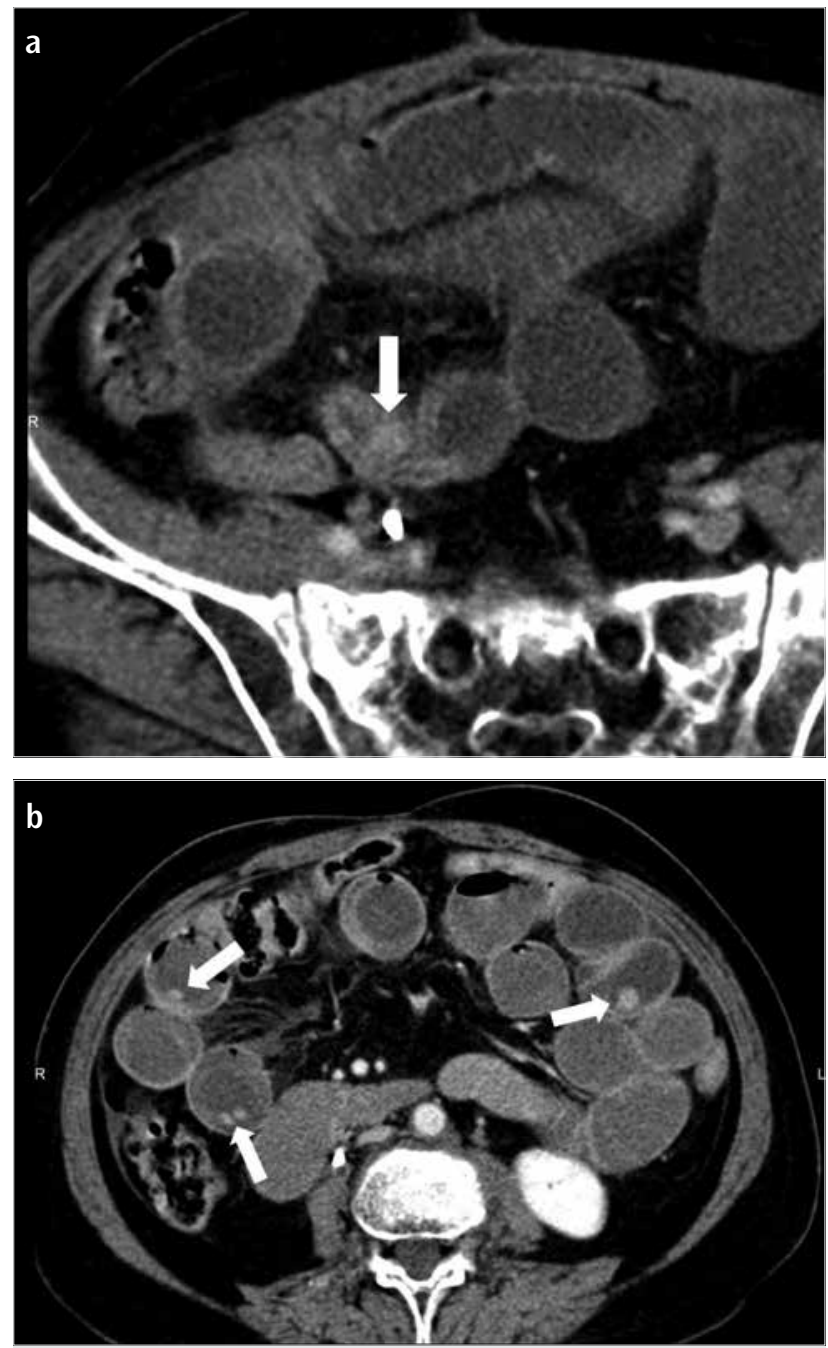

Figure 9. a, b. Axial CT of a 55-year-old female patient with intestinal obstruction shows intraluminal foreign body at the transition point level of obstruction (arrow). (a) In the same patient, similar foreign bodies are edema, and gas in the mesenteric vessels and portal vein may be seen in CT (49). An abnormal decrease in the intestinal wall contrast enhancement is a reliable finding for ischemia (8, 50).

\section{Treatment}

In the treatment, it is aimed especially to preserve fluid-electrolyte balance and to provide decompression in the gastrointestinal tract via the nasogastric catheter. If the clinical condition of the patient worsens and if there is an increase in the risk of distention, surgical intervention should be considered. In addition, surgical intervention can primarily be considered in the case of complete obstruction (13).
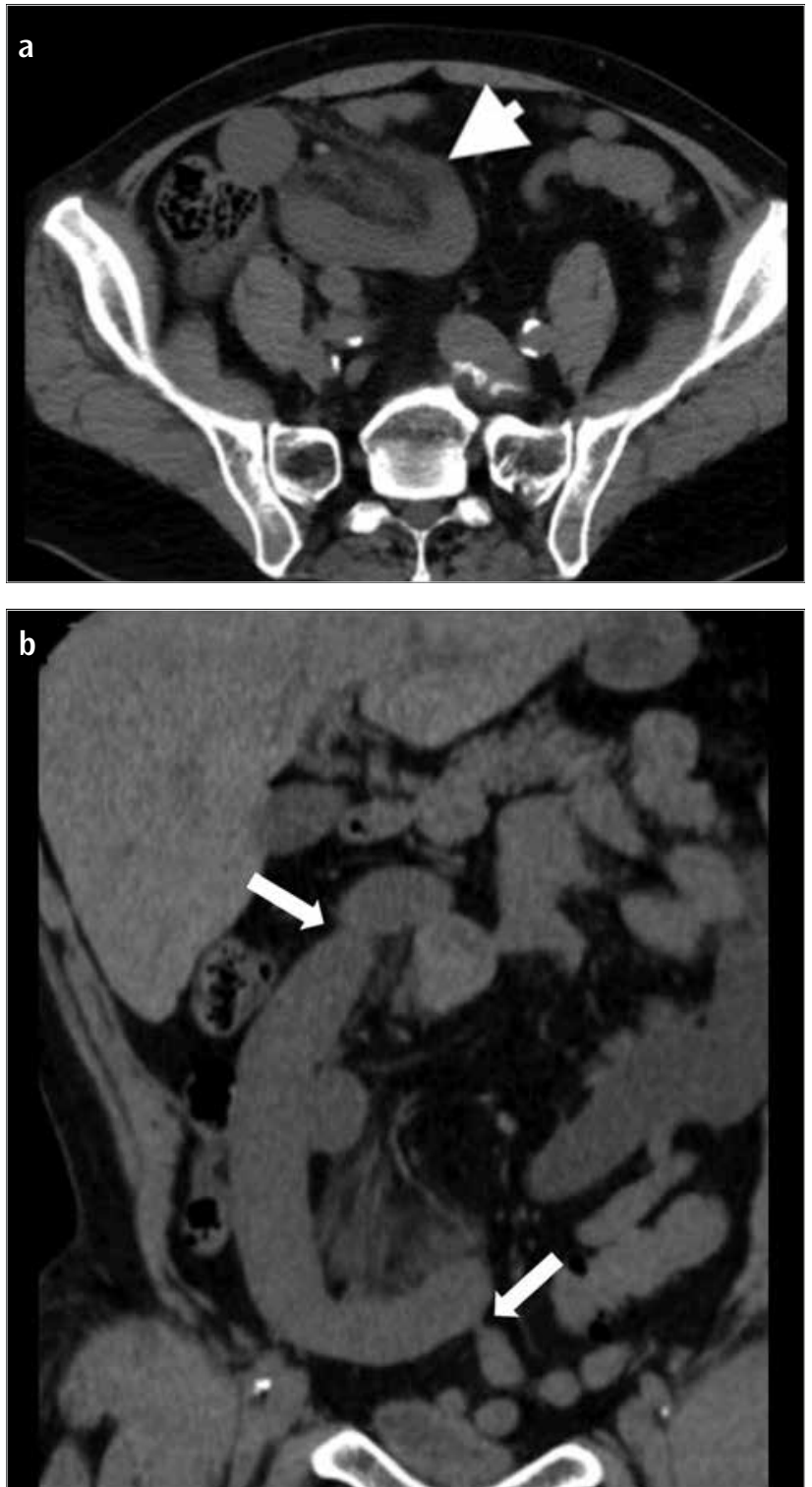

Figure 10. a, b. In a 57-year-old male patient with closed-loop small bowel obstruction, axial contrast-enhanced CT shows isolated dilatation of the small intestinal segment (arrow) and marked contamination in the adjacent mesenteric fat tissue. (a) In the coronal CT scan, the image of both proximal and distal transition points of this segment (arrows) and the absence of intestinal dilatation and contamination in the mesenteric fat tissue in other parts of the abdomen suggest closed-loop obstruction. (b) 


\section{Conclusions}

Intestinal obstruction is a picture that can be frequently encountered in the radiology practice because imaging and follow-up especially through CT is important. CT is the most appropriate imaging method for the diagnosis of intestinal obstruction and for determining the cause and transition point.

Peer-review: Externally peer-reviewed.

Author Contributions: Concept - O.T., E.Ü., M.R.O.; Design - O.T., M.R.O., E.A.; Supervision - E.Ü., M.R.O., E.A.; Resource - O.T., E.Ü., M.R.O.; Materials - O.T., M.R.O., E.A.; Data Collection and/or Processing - E.Ü., M.R.O., E.A.; Analysis and/or Interpretation - O.T., E.Ü., M.R.O.; Literature Search - O.T., M.R.O., E.A.; Writing - O.T., E.Ü., M.R.O.; Critical Reviews - M.R.O, E.A.

Conflict of Interest: The authors have no conflict of interest to declare.

Financial Disclosure: The authors declared that this study has received no financial support.

\section{References}

1. Taylor MR, Lalani N. Adult small bowel obstruction. Acad Emerg Med 2013; 200: 528-44. [CrossRef]

2. Cappell MS, Batke M. Mechanical obstruction of the small bowel and colon. Med Clin North Am 2008; 92: 575-97, viii. [CrossRef]

3. Gore RM, Silvers RI, Thakrar KH, Wenzke DR, Mehta UK, Newmark GM, et al. Bowel Obstruction. Radiol Clin North Am 2015; 53: 1225-40. [CrossRef]

4. Paulson EK, Thompson WM. Review of small-bowel obstruction: the diagnosis and when to worry. Radiology 2015; 275: 332-42. [CrossRef]

5. Thompson WM, Kilani RK, Smith BB, Thomas J, Jaffe TA, Delong DM, et al. Accuracy of abdominal radiography in acute small-bowel obstruction: does reviewer experience matter? AJR Am J Roentgenol 2007; 188: 233-8. [CrossRef]

6. Maglinte DD, Reyes BL, Harmon BH, Kelvin FM, Turner WW, Jr., Hage $\mathrm{JE}$, et al. Reliability and role of plain film radiography and $\mathrm{CT}$ in the diagnosis of small-bowel obstruction. AJR Am J Roentgenol 1996; 167 : 1451-5. [CrossRef]

7. Santillan CS. Computed tomography of small bowel obstruction. Radiol Clin North Am 2013; 51: 17-27. [CrossRef]

8. Zalcman M, Sy M, Donckier V, Closset J, Gansbeke DV. Helical CT signs in the diagnosis of intestinal ischemia in small-bowel obstruction. AJR Am J Roentgenol 2000; 175: 1601-7. [CrossRef]

9. Biondo S, Pares D, Frago R, Marti-Rague J, Kreisler E, De Oca J, et al. Large bowel obstruction: predictive factors for postoperative mortality. Dis Colon Rectum 2004; 47: 1889-97. [CrossRef]

10. Jaffe T, Thompson WM. Large-Bowel Obstruction in the Adult: Classic Radiographic and CT Findings, Etiology, and Mimics. Radiology 2015; 275:651-63. [CrossRef]

11. Krajewski K, Siewert B, Eisenberg RL. Colonic dilation. AJR Am J Roentgenol 2009 Nov; 193: 363-72. [CrossRef]

12. Frager D, Rovno HD, Baer JW, Bashist B, Friedman M. Prospective evaluation of colonic obstruction with computed tomography. Abdom Imaging 1998; 23: 141-6. [CrossRef]

13. Desser TS, Gross M. Multidetector row computed tomography of small bowel obstruction. Semin Ultrasound CT MR 2008; 29: 308-21. [CrossRef]

14. Horton KM, Fishman EK. The current status of multidetector row CT and three-dimensional imaging of the small bowel. Radiol Clin North Am 2003; 41: 199-212. [CrossRef]

15. O'Malley RG, Al-Hawary MM, Kaza RK, Wasnik AP, Platt JF, Francis IR. MDCT findings in small bowel obstruction: implications of the cause and presence of complications on treatment decisions. Abdom Imaging 2015; 40: 2248-62. [CrossRef]
16. Paulsen SR, Huprich JE, Fletcher JG, Booya F, Young BM, Fidler JL, et al. CT enterography as a diagnostic tool in evaluating small bowel disorders: review of clinical experience with over 700 cases. Radiographics 2006; 26: 641-57. [CrossRef]

17. Fukuya T, Hawes DR, Lu CC, Chang PJ, Barloon TJ. CT diagnosis of small-bowel obstruction: efficacy in 60 patients. AJR Am J Roentgenol 1992; 158: 765-9; discussion 71-2. [CrossRef]

18. Mayo-Smith WW, Wittenberg J, Bennett GL, Gervais DA, Gazelle GS, Mueller PR. The CT small bowel faeces sign: description and clinical significance. Clin Radiol 1995; 50: 765-7. [CrossRef]

19. Wittenberg J. The diagnosis of colonic obstruction on plain abdominal radiographs: start with the cecum, leave the rectum to last. AJR Am J Roentgenol 1993; 161: 443-4. [CrossRef]

20. Colon MJ, Telem DA, Wong D, Divino CM. The relevance of transition zones on computed tomography in the management of small bowel obstruction. Surgery 2010; 147: 373-7. [CrossRef]

21. Khurana B, Ledbetter S, McTavish J, Wiesner W, Ros PR. Bowel obstruction revealed by multidetector CT. AJR Am J Roentgenol 2002; 178 : 1139-44. [CrossRef]

22. Miller G, Boman J, Shrier I, Gordon PH. Etiology of small bowel obstruction. Am J Surg 2000; 180: 33-6. [CrossRef]

23. Silva AC, Pimenta M, Guimaraes LS. Small bowel obstruction: what to look for. Radiographics 2009; 29: 423-39. [CrossRef]

24. Akcalar S, Turkbey B, Karcaaltincaba M, Akpinar E, Akhan O. Small bowel wall thickening: MDCT evaluation in the emergency room. Emerg Radiol 2011; 18: 409-15. [CrossRef]

25. Al-Hawary MM, Kaza RK, Platt JF. CT enterography: concepts and advances in Crohn's disease imaging. Radiol Clin North Am 2013; 51: 1-16. [CrossRef]

26. Idelevich E, Kashtan H, Mavor E, Brenner B. Small bowel obstruction caused by secondary tumors. Surg Oncol 2006; 15: 29-32. [CrossRef]

27. Irvin GL 3rd, Horsley JS 3rd, Caruana JA Jr. The morbidity and mortality of emergent operations for colorectal disease. Ann Surg 1984; 199: 598-603. [CrossRef]

28. Horton KM, Abrams RA, Fishman EK. Spiral CT of colon cancer: imaging features and role in management. Radiographics 2000; 20: 41930. [CrossRef]

29. Rea JD, Lockhart ME, Yarbrough DE, Leeth RR, Bledsoe SE, Clements RH. Approach to management of intussusception in adults: a new paradigm in the computed tomography era. Am Surg 2007; 73: 1098-105.

30. Maturen KE, Feng MU, Wasnik AP, Azar SF, Appelman HD, Francis IR, et al. Imaging effects of radiation therapy in the abdomen and pelvis: evaluating "innocent bystander" tissues. Radiographics 2013; 33: 599-619. [CrossRef]

31. Taourel P, Kessler N, Lesnik A, Pujol J, Morcos L, Bruel JM. Helical CT of large bowel obstruction. Abdom Imaging 2003; 28: 267-75. [CrossRef]

32. Horton KM, Corl FM, Fishman EK. CT evaluation of the colon: inflammatory disease. Radiographics 2000; 20: 399-418. [CrossRef]

33. Sai VF, Velayos F, Neuhaus J, Westphalen AC. Colonoscopy after CT diagnosis of diverticulitis to exclude colon cancer: a systematic literature review. Radiology 2012; 263: 383-90. [CrossRef]

34. Caoili EM, Paulson EK. CT of small-bowel obstruction: another perspective using multiplanar reformations. AJR Am J Roentgenol. 2000: 174: 993-8. [CrossRef]

35. Attard JA, MacLean AR. Adhesive small bowel obstruction: epidemiology, biology and prevention. Can J Surg 2007; 50: 291-300.

36. Aguirre DA, Casola G, Sirlin C. Abdominal wall hernias: MDCT findings. AJR Am J Roentgenol 2004; 183: 681-90. [CrossRef]

37. Ballantyne GH, Brandner MD, Beart RW Jr., Ilstrup DM. Volvulus of the colon. Incidence and mortality. Ann Surg 1985; 202: 83-92. [CrossRef]

38. Peterson CM, Anderson JS, Hara AK, Carenza JW, Menias CO. Volvulus of the gastrointestinal tract: appearances at multimodality imaging. Radiographics 2009; 29:1281-93. [CrossRef]

39. Delabrousse E, Bartholomot B, Sohm O, Wallerand H, Kastler B. Gallstone ileus: CT findings. Eur Radiol 2000; 10: 938-40. [CrossRef]

40. Colombo C, Ellemunter H, Houwen R, Munck A, Taylor C, Wilschanski M. Guidelines for the diagnosis and management of distal intestinal obstruction syndrome in cystic fibrosis patients. J Cyst Fibros 2011; 10: 24-8. [CrossRef] 
41. Delabrousse E, Brunelle S, Saguet O, Destrumelle N, Landecy G, Kastler B. Small bowel obstruction secondary to phytobezoar CT findings. Clin Imaging 2001; 25: 44-6. [CrossRef]

42. George C, Al-Zwae K, Nair S, Cast JE. Computed tomography appearances of sclerosing encapsulating peritonitis. Clin Radiol 2007; 62: 732-7. [CrossRef]

43. Agrawal GA, Johnson PT, Fishman EK. Intermittent small bowel obstruction with retained endoscopic capsule: MDCT and plain radiographic appearance. Emerg Radiol 2007; 13: 319-21. [CrossRef]

44. Sandhu PS, Joe BN, Coakley FV, Qayyum A, Webb EM, Yeh BM. Bowel transition points: multiplicity and posterior location at CT are associated with small-bowel volvulus. Radiology 2007; 245: 160-7. [CrossRef]

45. Capella RF, lannace VA, Capella JF. Bowel obstruction after open and laparoscopic gastric bypass surgery for morbid obesity. J Am Coll Surg 2006; 203: 328-35. [CrossRef]

46. Frager DH, Baer JW, Rothpearl A, Bossart PA. Distinction between postoperative ileus and mechanical small-bowel obstruction: value of CT compared with clinical and other radiographic findings. AJR Am J Roentgenol 1995; 164: 891-4. [CrossRef]
47. Duda JB, Bhatt S, Dogra VS. Utility of CT whirl sign in guiding management of small-bowel obstruction. AJR Am J Roentgenol 2008; 191: 743-7. [CrossRef]

48. Mallo RD, Salem L, Lalani T, Flum DR. Computed tomography diagnosis of ischemia and complete obstruction in small bowel obstruction: a systematic review. J Gastrointest Surg 2005; 9: 690-4. [CrossRef]

49. Jancelewicz T, Vu LT, Shawo AE, Yeh B, Gasper WJ, Harris HW. Predicting strangulated small bowel obstruction: an old problem revisited. J Gastrointest Surg 2009; 13: 93-9. [CrossRef]

50. Sheedy SP, Earnest Ft, Fletcher JG, Fidler JL, Hoskin TL. CT of small-bowel ischemia associated with obstruction in emergency department patients: diagnostic performance evaluation. Radiology 2006; 241: 729-36. [CrossRef]

Cite this article as: Taydaș 0, Ünal E, Onur MR, Akpınar E. Role of Computed Tomography in Intestinal Obtruction. İstanbul Med J 2018; 19: 105-12. 